\title{
What is Global Expressivism?
}

\author{
Matthew Simpson
}

Note This is the final version as of March 23, 2019 submitted for publication at Philosophical Quarterly

\begin{abstract}
Global expressivism is the radical view that we should never think of any of our language and thought as representing the world. While interesting, global expressivism has not yet been clearly formulated, and its defenders often use unexplained terms of art to characterise their view. I fix this problem by carefully and clearly exploring the different ways in which we can interpret globalism. I reject almost all of them either because they are implausible or because they are bad interpretations of actual globalist views. I then argue that the most promising version of globalism, which we can find in the work of Huw Price, turns out to be completely compatible with the view of so-called 'local' expressivists. The debate between globalists and localists is therefore empty: the real interest in this topic lies not in this debate but in whether globalism is true and if so what follows from it.
\end{abstract}

\section{Keywords}

Global expressivism; Expressivism; Deflationism; Pragmatism; Representation

\section{Introduction}

Metaethical expressivism is the now familiar view that ethical statements are best thought of not as representing or describing the world but as expressing our attitudes towards it. Global expressivists like Huw Price and Michael Williams think that some element of this view can be extended to cover all statements: they say that no language is representational or descriptive. Local expressivists like Simon Blackburn and Allan Gibbard disagree: expressivism may be true of some kinds of statements, but it is not true of all of them. 
Those sceptical of metaethical expressivism may find globalism an absurd proposal, and globalists themselves have argued that it is indeed a radical view with radical consequences. Huw Price and David Macarthur (2007) claim that globalism opposes the 'deeply entrenched' representationalist view that the primary function of language is to represent the world. They take representationalism to be a 'dogma' of contemporary philosophy which is so orthodox that it is almost 'invisible'. Rejecting it, they argue, leads to widespread metaphysical quietism, since most contemporary metaphysics rests on representationalist assumptions. This result would be radical indeed.

Despite increasing interest, global expressivism has yet to be clearly formulated. Many writers in the debate use unexplained terms of art to characterise the view, for instance by characterising globalism as the view that representation is not 'robust' or 'substantial' but only 'minimal'. This has made it difficult to clearly and carefully evaluate the view and determine its wider consequences. It also makes the debate look to an outsider like an obscure dispute that can be happily disregarded, like the enmity between Monty Python's People's Front of Judea and the Judean People's Front. This is a shame, since both local and global expressivism are interesting views and they potentially have significant consequences of interest to philosophy of language, mind, and metaphysics.

In this paper I fix this problem. I discuss and develop the different interpretations of global expressivism implicit in the literature, and I argue that the best interpretation takes globalism to be the view that a certain class of concepts including representation, belief, and description have no role to play in certain kinds of explanations of aspects of our language. I give an account of the kinds of explanations expressivists are concerned with, and then explore the different ways writers characterise the class of concepts to be excluded from these explanations. This yields a handful of different interpretations of globalism (and so localism).

The result is mixed news for globalists. While there are several interpretations of globalism that make it coherent and clear, there is no interpretation which makes globalism plausible, a good interpretation of actual globalist views, distinct from mainstream non-expressivist theories, and distinct from local expressivism. Four of the five globalist views I discuss fail to meet one of the first three conditions. Moreover, the most plausible version of globalism, Huw Price's version, is actually not distinct from localism, and so the debate between Price and localists like Blackburn and Gibbard is empty, a verbal debate about what 'global expressivism' means. This surprising result casts doubt on globalism's radical ambitions. 


\section{Expressivism and Representation}

Global expressivism is meant to generalise some element of metaethical expressivism. Something metaethical expressivists say about ethical language and thought is to be applied to all language and thought. Localists then say that whatever this is, it can only be true of some kinds of language.

But what part of metaethical expressivism does globalism generalise? The famous slogan is that ethical language expresses attitudes, which somehow differ from ordinary beliefs. This really has two parts: (a) ethical mental states are attitudes and (b) ethical language expresses them. The claim about ethical mental states supports a claim about ethical language. On top of this slogan, we have Blackburn's quasi-realist project of explaining why we express attitudes using claims that are importantly similar to those we use to express ordinary beliefs which can be called true and false, can be embedded in complex contexts, and so on.

Immediately it's clear that neither (a) nor (b) is suitable for generalising. (b) is just a specific version of an ideationalist or psychologistic approach to meaning, according to which language means what it does in virtue of expressing mental states with certain contents. It isn't inherently expressivist - you can accept (b) yet think that ethical mental states aren't attitudes but full-blown beliefs. So (b) can't be what is generalised; the resulting view would be a global psychologistic theory of meaning, not a global expressivism.

Interestingly, in a recent article Allan Gibbard seems to take (b) as the core of expressivism, which he says 'explain[s] the meaning of the word via explaining the states of mind that constitute believing things couched with the term' (2015, 212). However, Gibbard admits that his definition is idiosyncratic $(2015,213)$, and as we'll see in $\S 7$ his commitment to local expressivism is best understood in other ways. So for now we'll sideline (b) and Gibbard's definition.

Component (a) can't be what is generalised either. First, not all global expressivists will think that for every kind of language, there is a corresponding distinctive mental state expressed by statements of that kind. For instance, Huw Price thinks that the truth predicate needs a theory which is relevantly similar to metaethical expressivism, but he denies that sentences using that predicate express a distinctive state of mind $(2013,177)$.

Second, even if globalists do think that each kind of statement expresses a distinctive kind of mental state, they will not think that all statements express attitudes like ethical statements do. For instance, Simon Blackburn also defends expressivism about causal and modal language, but he doesn't think that causal and modal statements express ethical attitudes. Instead they express inferential dispositions. Mark Schroeder (2008), who argues that ethical expressivists should end up treating all beliefs as non-cognitive states of 'being for', doesn't think 
expressivists should end up treating all beliefs as states of being for blaming, which he takes to be distinctive of (some) ethical mental states. If Schroeder's suggestion qualifies as a global expressivism, it is not because it's a generalisation of the metaethical expressivists' specific claim about attitudes.

Instead, the core component of expressivism is a suspicion of notions like belief, representation and truth. For simplicity, call these representational features. Implicit in (a) is the idea that the attitudes expressed by ethical language are best understood without these features. And Blackburn thinks that causal and modal thoughts are like this too - even though they aren't attitudes, they shouldn't be characterised in terms of belief, truth-conditions, representation, and so on. Sometimes this idea is expressed as the view that the relevant mental states - and consequently the language which expresses them - are non-cognitive, or non-representational. It's this general contrast, between representational and non-representational states, that matters here. ${ }^{1}$

Consequently, we should see the core component of metaethical expressivism as a suspicion of representational features - features like representation, truth, and belief - as applied to ethical language and thought. Globalism generalises this: it is suspicious of representational features as applied to any kind of language. This raises the question of how to understand this suspicion. ${ }^{2}$

A natural starting point is to take metaethical expressivists as straightforwardly denying that ethical language and thought is representational, that ethical mental states are beliefs, that ethical sentences are truth-apt. This was the view of expressivism's emotivist ancestors, like Ayer (1936). It was also the earlier view of prominent expressivists like Gibbard (1990, 8) and Blackburn (1984, 167). Many writers still think that it is the essential core of expressivism. This view is an outright rejection of representation, truth, and the like as applied to ethical language.

However, we shouldn't read global expressivism like this. It would require saying that no language expresses beliefs, no language represents, no sentences have truth-conditions. This is implausible. Frank Jackson claims that Price's global expressivism is false since 'it is obvious that much of language is representational' $(1997,270)$.

Even if Jackson's objection is too quick, the rejection view isn't a generalisation of what contemporary expressivists actually say about ethical language. Prominent expressivists like Blackburn and Gibbard now accept that ethical lan-

\footnotetext{
${ }^{1}$ This also makes sense of Schroeder's view, since his proposal to take all beliefs as noncognitive states of 'being for' fits into this schema.

2 This point shows how inappropriate the label 'expressivism' is for the global view, since that term is so closely associated with metaethics. Indeed, Price himself agrees that 'the terms 'expressivism' and 'global expressivism' are to some extent unhappy' $(2013,176)$. The most common alternative label here is 'pragmatism', though this is hardly better given its wide range of uses. I will stick to 'expressivism' for simplicity.
} 
guage is representational, states facts, has truth-conditions, and so on (see Gibbard, 2015; Blackburn, 2015). It is these newer versions of expressivism which global expressivists aim to generalise (see e.g. Price, 2015, 137). So the general rejection of representational features is not a good reading of actual expressivist views, local or global.

While this might protect globalists from objections like Jackson's, it raises new questions. If expressivists don't reject representational features in the case of ethical language, what exactly is their suspicion of such notions, and how does this suspicion generalise?

\section{3 'Robust' representation?}

One common route is to distinguish two senses of representation (and other notions, but I'll focus on representation for simplicity): 'thin', 'minimal', 'insubstantial', 'deflated', 'lowercase' representation (and the like) on the one hand, and 'thick', 'robust', 'substantial', 'inflated', 'uppercase' 'Representation' on the other. Metaethical expressivism then involves the view that ethical language only represents the world in the first, minimal sense; it does not represent in the robust sense. Globalism then says that no language robustly Represents the world; it only represents in the minimal sense.

Terms like 'substantial', 'thin' and 'robust' are not hard to find in the literature. $^{3}$ But as many have pointed out, they are very vague, and expressivists seldom discuss their precise meanings. For instance, in a review of Huw Price's (2013), John MacFarlane worries about words like these:

There is so little explicit attention to this issue [of what such terms mean] ... that I sometimes felt like an imposter: if you have to ask, you shouldn't be here! (MacFarlane, 2014, 4)

This has fostered a kind of pessimism about contemporary expressivism and its generalised form: the expressivists' argot cannot be made clear and therefore expressivism cannot be examined properly. ${ }^{4}$

I think terms like 'robust' are dispensable, and indeed unhelpful to expressivism and its proper evaluation. However, it's worth seeing how they're used in

\footnotetext{
3 See for example Price (2011, 2013); Lenman (2003); Sinclair (2006); Blackburn (2013); Williams (2013); Dreier (2004); deVries (2011); Nye (2015).

${ }^{4}$ Indeed as MacFarlane's claim suggests, these terms encourage an image of debates about expressivism and related positions as inaccessible to those not already in the know. Whether or not this impression is accurate, it would be a shame if it stuck, and expressivists themselves would benefit if it were dispelled. One aim of this paper is to do so, and therefore to allow wider and clearer debate of these views.
} 
the literature. As far as I can see there are two primary uses: an environmental use, and an explanatory one. Roughly, a term robustly represents in the environmental sense if it represents the speaker's external environment in a certain way. It robustly represents in the explanatory sense if representation plays a role in certain explanations of features of that term - I won't say which explanations yet, as it's the task of the next section to work this out.

Before I make these notions clear, note that they yield independent distinctions. The environmental sense distinguishes two kinds of representation, environmental and non-environmental representation. The explanatory sense does not distinguish kinds of representation, but distinguishes the uses to which representation is put, namely whether it has a role in certain explanations of our language. As a result, both of these notions of robustness and their corresponding distinctions can be employed at the same time, as they are in (Price, 2015) for example. One can accept that a term robustly represents in one sense but not the other, or in both senses, or neither. Recognising this makes the literature slightly easier to follow.

So, let's now explore these two notions of robustness and ask whether we can generalise expressivism using either. Let's start with the environmental notion. A term represents in the environmental sense just in case it bears some kind of causal tracking relation to elements of speakers' physical surroundings, so that typically the term is uttered when and only when a certain element is present in the environment. Blackburn says that 'Environmental representation is essentially a matter of causal covariation', comparing it with what 'petrol gauges, voltmeters' and 'windsocks' do. (Blackburn, 2010, 10). Price characterises 'e-representation' like so:

... the crucial idea is that some feature of the representing system either does, or is (in some sense) 'intended to', vary in parallel with some feature of the represented system. ... the function of [an e-]representation is to co-vary with some (typically) external environmental condition ... (Price, 2013, 36)

A term represents its environment if it bears some kind of relation of co-variation with some aspect of the speaker's external environment. Ethical expressivists deny that ethical terms represent their environment in this sense: their function isn't to track the moral features of the environment, but to express attitudes.

The generalisation of ethical expressivists' rejection of environmental representation is

(GEV) No term represents its environment.

However, even with only a rough understanding of environmental representation, we can see that this isn't right. It's a bad reading of global expressivism, and it's 
independently implausible. It's implausible because there clearly are terms which causally track their environment. Uses of terms like 'tree', 'chair' and so on are causally sensitive to speakers' beliefs about trees and chairs. Since such beliefs typically are also sensitive to the presence of such things, these terms are causally sensitive to their presence too. Arguing that there are no terms which do this is a tough task.

Even if this objection fails, (GEV) is still a bad reading of globalism. Globalists admit that there are terms which represent their environment. Price doesn't introduce the category of 'e-representation' to argue that it's empty! Similarly, Michael Williams accepts that there are terms like this, for instance colour terms like 'red' (2013, 140), and Price endorses his example. So whether or not (GEV) is plausible, it's a bad reading of global expressivism. Global expressivism isn't the view that no terms represent their environment.

One might object that while globalists accept that some terms represent their environment in the above sense, they will deny that this fact is relevant for the proper explanation of those terms. ${ }^{5}$ Recall that since the environmental and explanatory readings of robustness are independent, globalists can accept that terms represent in the environmental but not the explanatory sense. This would let us distinguish globalism and localism in terms of environmental representation: localists think that some language represents its environment and that this is relevant for certain explanations of that language, while globalists will think that environmental representation is simply never relevant. In $\S 5$ I will refute this objection. However, note that it reveals that the more important notion for this debate is not the environmental one but the explanatory one: if the objection succeeds, this is because of the claim about the explanatory relevance of environmental representation. So it's time to turn to the explanatory notion and ask whether we can get a plausible reading of global expressivism from that.

\section{Representation and Explanation}

On the explanatory reading of robustness, a term robustly represents just in case representation plays a crucial role in a distinctive kind of explanation of that term. To say that a term minimally represents is therefore to say something that has no (indispensable) role in explanations of this kind. The primary task of this section is to say what explanations expressivists have in mind. The idea of representation's explanatory role is increasingly popular in the literature. For instance, here are Blackburn, Gibbard, Price and Williams - two localists and two globalists:

Where pragmatism [which Blackburn takes to include expressivism]

\footnotetext{
5 Thanks to an anonymous reviewer for raising this.
} 
is distinctive is in holding that representation is nevertheless not the key concept to deploy when the desire for philosophical explanation of our practice in some area is upon us. It is not the way to understand the kind of thought or the part of language in question ... (Blackburn, $2015,851)$

Whereas standard 'representationalist' views invoke substantial notions of denotation and the like to explain the workings of thinking and language, expressivists treat representation by deflation [i.e. by excluding it from these explanations]. (Gibbard, 2015, 211)

I am not proposing merely that genuine representation turns out to be a linguistic function that is not in play in our own language, but that representation ... is a theoretical [i.e. explanatory] category we should dispense with altogether. The right thing to do, as theorists ... is to stop talking about representation altogether, to abandon the project of theorising about word-world relations in these terms. (Price, 2011, 10)

Representationalists explain the (proper) use of vocabulary items in terms of their meanings, and explain meaning (at least of non-logical vocabulary) in terms of semantic (word-world) relations, such as reference. By contrast, antirepresentationalists eschew the use of semantic notions as explanatory primitives. (Williams, 2013, 128)

Here, and in other places in the literature, we find the explanatory role of representation and related notions as the primary target of expressivism both local and global. Indeed the term 'representationalism' is used to mean the view which gives representation such a role, as is clear in the quotes above. ${ }^{6}$ On this view, global expressivism is the view that representation and related notions never have a role to play in certain kinds of explanation of elements of human language. Now I will say what kinds of explanations expressivists have in mind.

While expressivists disagree on the exact nature of these explanations, there is a significant core of agreement here. I think that expressivists in general are interested in explanations which have two components. The first explains the features the target terms have in virtue of which they mean what they do. The second explains why human beings use terms with these features. I will now say more about these explanations.

\footnotetext{
${ }^{6}$ See also Gross et al. (2015), Price (2004, 209), Price \& O'Leary-Hawthorne (1996, 115), Blackburn (2010, 172), Chrisman (2011), Dreier (2004, 2018) and Ridge (2014, 103ff), Toppinen (2015), Zalabardo (Forthcoming).
} 
The first component of an expressivist explanation says what makes the relevant term mean what it does. For instance, in the ethical case, this will involve saying what it is about the word 'wrong' that makes it mean wrong rather than something else. This will usually involve talking about the basic assertions involving that word, in this case claims of the form ' $\mathrm{x}$ is wrong'. What makes such claims mean $x$ is wrong rather than, say, $x$ is blue? In the ethical case, the expressivist's answer is that such assertions express practical attitudes, and this is why they mean what they do. More generally, they will say that to make an ethical assertion just is to express an attitude of the relevant sort.

This explanation is often called a metasemantic one. ${ }^{7}$ It is not about what the term in question means, or about its compositional contribution to meanings of sentences it appears in, but about why it means what it does, what about it makes it mean what it does. James Dreier (2004) argues that this is the central distinctive expressivist claim - saying what constitutes ethical meaning.

Some expressivists, like Price, tend to talk about use rather than meaning. ${ }^{8}$ They seek accounts of what explains the use of the relevant terms, and as before these typically focus on the use of those terms in assertions. So for Price, the question about ethical language is: what facts about the term 'wrong' explain the fact that it is used as it is, in particular in assertions of the form ' $x$ is wrong'? Interestingly, for Paul Horwich $(1998,45)$, the answer to this question just is a constitutive claim about ethical meaning, the sort of claim Dreier is interested in. If we can specify generalisations which explain why people say things of the form ' $x$ is wrong' when they do, we have given the kind of explanation both Price and Horwich are after.

The second component of the expressivist's explanation is to say why human beings have the features mentioned in the first component. We said what features made the terms mean what they do: now we ask why we have terms with such features. In ethics, expressivists offer a sketch of a genealogy showing why it would be beneficial for humans to have words and declarative sentences that express attitudes. Price is particularly interested in this component of expressivist explanations (Price, 2013, 20).

This two-part explanation is common in the literature. The best example is from Blackburn, who claims that you are an expressivist about an area of language and thought if you ask the question:

$[\mathrm{H}]$ ow does it come about that we go in for this kind of discourse and thought? What is the explanation of this bit of our language game? And then you offer an account [which] eschews any use of the refer-

\footnotetext{
7 See Chrisman (2016, ch.6) and Ridge (2014, ch.4) for examples of this term in use.

${ }^{8}$ See for instance Price (2013, ch.1), in which Price talks about use rather than meaning, and mentions meaning as a suspicious category.
} 
ring expressions of the discourse; $\ldots$ or any semantic or ontological attempt to 'interpret' the discourse in a domain, to find referents for its terms, or truth makers for its sentences ... Instead the explanation proceeds by talking in different terms of what is done by so talking. It offers a revelatory genealogy or anthropology or even a just-so story about how this mode of talking and thinking and practising might come about, given in terms of the functions it serves. (Blackburn, $2013,75)$

Here, 'an account of what we are up to', of 'what is done by so talking' is the first component, saying what is going on that makes the language meaningful. Saying how it comes about 'that we go in for this kind of discourse and thought' is the second component. The kinds of answer Blackburn wants to eschew involve representational features (reference, truth, and so on). The focus on 'what is done' by using these terms partly explains why expressivism is now often labelled as a pragmatist view, which is a label Blackburn uses, though as I noted earlier I will stick with 'expressivism' here. The two-part idea can also be found elsewhere in the work of both localists and globalists. ${ }^{9}$

On this reading, globalism is the view that for any given term, we can say what features it has that explain why it means what it does, and why humans have terms with those features, without saying that the term has representational features. ${ }^{10}$ In other words, we can explain assertions in general, assertions about anything at all, without invoking representation and the like. We can sum up globalism like so:

(GER) There is no term $t$ such that the best explanation of $t$ 's meaning and use requires treating $t$ as representational

Here I stipulate an 'explanation of t's meaning and use' to mean the distinctive two-part expressivist explanation I described above. So while other projects - for instance explaining the difference between declaratives, imperatives, and interrogatives - would ordinarily count as explaining meaning, or explaining language, I don't mean such things here. I include use to allow for expressivists who prefer it to meaning. I also leave 'treating as representational' open, to accommodate the disagreement between expressivists about which features count as representational.

So according to (GER), we can say why terms mean what they do, and get used as they do, without appealing to representational features. This yields a nice

\footnotetext{
${ }^{9}$ See Gibbard (2003, p.xii), Price (2013, 20), Williams (2013, 134ff).

10 This includes saying why 'represents' means represents, 'refers' means refers, and so on. See Price (2013, ch.1), Macarthur \& Price (2007); Price (2015) for more on this issue.
} 
definition of localism too: we can explain some kinds of terms without representation, but not all of them. It also lets us dispense with the word 'robust', or at least understand what it means. When globalists say they globally reject robust representation, on this reading they mean they never use representation in these distinctive two-part explanations.

\section{Interpreting Representation}

(GER), therefore, is the best reading of globalism so far. It generalises the core claim of metaethical expressivism, that ethical language can be explained without representation. However, this reading still faces problems. The first concerns the range of features which count as representational. Expressivists (local and global alike) have thought that various different features and notions concerning language and thought fall in this category, including: representation, reference, truth-conditions, truth, truth-aptitude, belief, and description. ${ }^{11}$ However, no expressivist has given a definitive account of what features count as representational, beyond a list (see e.g. Price 2013, 149-150, who borrows from Kraut 1990). The less we know about the features concerned, the less clear a picture we have of global expressivism, and so the less able we are to assess it and its putative consequences.

I think we should at least try to give a deeper characterisation of representational features. It is more illuminating than a list, and the aim of this paper is to illuminate expressivism as much as possible. ${ }^{12}$ And in fact, in the case of metaethical expressivism I think we can give such a characterisation.

The promising option here is to invoke the notion of subject matter. Dreier (2004, 37ff) argues that expressivists do not use ethical facts and properties when they explain ethical language and thought in the constitutive way I mentioned in $\S 4$, and this distinguishes expressivism from its rivals. I think Dreier's specific claim is slightly too ontologically committing: even though expressivists don't appeal to ethical facts and properties, not all rivals to expressivism will appeal to such things. Expressivists would also object to a view which explains ethical terms by saying that they represent things as good, wrong, and so on, but treats this as primitive. Some may want to explain ethical language in terms of Fregean propositions, which are composed of senses or concepts and not entities and properties. And error theorists may not want to believe in ethical facts and properties at all, but still think that we have to understand, say, the thought that $\mathrm{x}$ is wrong

\footnotetext{
${ }^{11}$ See Kraut $(1990,159)$ for fuller, though not exhaustive, list of these.

12 There is a distinct worry here about reductionist accounts of representation. A referee convinced me that this is not particularly important here. See also (Simpson, 2018) for a discussion of it.
} 
in terms of something like representing $x$ as wrong or believing $x$ to be wrong, or ascribing wrongness to $x$, even if wrongness does not exist. These views oppose expressivism but don't obviously appeal to ethical facts and properties. ${ }^{13}$

However, we can understand these rival views in terms of the notion of subject matter - they explain ethical language in terms of what that language is about, whether or not this actually exists. This suggests a general idea: that to treat a term as representational is to invoke its subject matter in its explanation. This yields an understanding of global expressivism:

(GSM) There is no term $t$ such that the best explanation of $t$ 's meaning and use cites $t$ 's subject matter.

and local expressivism:

(LSM) For some but not all terms $t$, the best explanation of the meaning and use of $t$ doesn't require mentioning $t$ 's subject matter.

Unfortunately, I'll now show that (GSM) is both questionable and a bad interpretation of globalism. (Later I'll argue that in contrast, (LSM) is a very good interpretation of local expressivism, which is why the debate between localism and globalism is merely verbal.)

The reason (GSM) is questionable is that the cases of environmental representation which I discussed in $\S 3$ are counterexamples to it. Earlier I argued that even global expressivists will accept that some terms represent their environment in the sense outlined above. More or less the same argument shows that (GSM) isn't a good reading of globalism. However there's a key difference. My claim before was that some terms do bear tracking relations to their environment. Now my claim is that some terms' meaning and use is best explained in terms of these relations, and that globalists accept this too.

What (GSM) says is that you can explain any term's meaning and use without citing its corresponding subject matter. You can explain why 'tree' is used as it does without invoking trees, why 'London' means London without invoking London, and so on. This is implausible for terms we use to describe our environment. For instance, even if you think that the causal relation between utterances the English word 'tree' and trees is not by itself responsible for the fact that 'tree' means tree, it is a further step to say that this relation has no bearing at all on that fact. If English speakers' utterances of the term 'tree' were utterly insensitive to the presence or absence of trees, it would be reasonable to say that 'tree' would not mean tree.

So some kind of relation between 'tree' and trees, whatever that relation comes to, does seem to be a necessary component of what makes 'tree' mean what it

\footnotetext{
${ }^{13}$ See (Simpson, 2018) for a lengthier discussion of this problem.
} 
does. This isn't merely to say that 'tree' causally tracks trees, but that its doing this is part of what makes it mean what it does. Moreover, if 'tree' were not causally sensitive to the presence of trees, it would not be used in the way it in fact is, since its actual use is sensitive in this way. So (GSM) is falsified by 'tree' and other terms like it, plausibly including natural kind terms and other terms we use to describe our physical environment.

So it seems more plausible to say not only that there are some terms which bear relations to their subject matter, but that there are terms whose meaning and use is best explained in terms of such relations. And this means that (GSM) is false. However, even if you are not convinced by the argument, there is a further point: globalists themselves will accept this. To see this let's look at Williams and Price.

Williams says there are terms whose explanation involves speakers' 'RDRD's, reliable discriminative reporting dispositions. He gives 'red' as an example:

To master 'red' in its reporting use, the speaker must have a reliable discriminative reporting disposition (RDRD): a disposition, given appropriate motivation and conditions, to report ' $\mathrm{x}$ is red' only in the presence of a red thing in his field of vision. (Williams, 2013, 140)

For Williams, then, the explanation of why 'red' means red necessarily involves a link between 'red' and red things - a link mediated by speakers' perceptions. Note that Williams is not merely saying that people have RDRDs regarding red things, but that 'red' gets its meaning in virtue of them. He makes the above claim in the context of sketching what he calls an 'EMU' - an explanation of meaning in terms of use - for 'red' $(2013,133)$. The claim about RDRDs is clearly meant to be explanatory. So Williams certainly accepts counterexamples to (GSM).

It's not clear whether Price accepts that some terms are to be explained in terms of their 'e-representation', as he puts it (Price 2015, 147, Price 2013, 36ff, 175ff). However, note that he approvingly cites Williams' case of 'red' as a case where the best explanation of the term invokes e-representation (Price, 2013, 175). Moreover, Price has good philosophical reason to accept that there are cases like this. Price's main concern is to causally-historically explain patterns of linguistic use:

The challenge [for the expressivist] is now simply to explain in naturalistic terms how creatures like us come to talk in these various ways. (Price, 2013, 20)

Environmental representation often involves a notion of tracking, cashed out in a causal way: utterances of a given term are caused by the (perceived) presence of a given object. In the case of 'red', speakers with the right RDRD are disposed to 
report ' $\mathrm{x}$ is red' only when there is a red thing visible. But this is clearly part of an explanation of why the claim is uttered: the speaker's RDRD, plus the presence of a red thing, plus the link between RDRDs and her understanding of the word 'red' explain why she said ' $\mathrm{x}$ is red'. So here the link between 'red' and the red thing - a link which counts as environmental representation - is not only present but also explains why the term is uttered. Price has no good reason to deny this.

To conclude this section: (GSM) is no good - it doesn't match the literature and it looks implausible. If we want to understand global expressivism as excluding representational features from all explanations of meaning and use, we will have to give a different interpretation of what representational features are. In the next section I will suggest such a reading which I think gives the best interpretation of globalism.

\section{Generality}

So far, we've had no luck in characterising global expressivism in a way which makes it both plausible and faithful to actual globalists' work. However, there is one plausible interpretation of globalism left, concerning whether representation and the like are in some sense general.

In his defences of global expressivism, Huw Price frequently mentions generality: he talks about whether representation and other notions are uniform or univocal (Price, 2011, 32-3), whether all meaningful descriptive sentences have something in common which explains them (Price, 2004, 201), and whether we should think of all sentences in language as being "about' some aspect of the external world, in much the same way' (Price, 2013, 40, emphasis added). Price summarises his view like so:

In particular, it is open to us to take the view that at least by the time we get to language, there is no useful external notion, of a semantic kind -in other words, no useful, general, notion of relations that words and sentences bear to the external world, that we might usefully identify with truth and reference. ${ }^{14}$ (Price 2015, 146-7; see also Price 2011, 21)

Taking Price's term 'useful' to concern explanation, in the sense we've been discussing, this amounts to a denial that there are any properties of language which satisfy these three conditions: (i) they are relations between language and the world, (ii) they explain terms' meaning and use, and (iii) they are general. In

\footnotetext{
${ }^{14}$ Price sometimes calls this view 'semantic minimalism'. I won't mention this again, as it needs a more thorough explanation to distinguish it from the various minimalist theories of truth, reference, and similar notions.
} 
other words, Price thinks that no term's meaning is explained by its possession of a relational property which is general. We can now reconfigure (GER) to get a new claim:

(GEG) There is no term $t$ such that the best explanation of $t$ 's meaning and use requires ascriptions to $t$ of a general relation between language and the world.

Now we need to understand what 'general' might mean, and whether this gives global expressivism any more hope. Note also that Price talks in terms of relations between language and the world, rather than terms and their subject matter. This will be important shortly.

I think we should understand generality in terms of kinds: a general relation is one that explains all terms of a given kind. Then (GEG) says that for a given kind of term, there is no relation which all terms of that kind bear to the world, and which explains their meaning and use. So for instance, if singular terms formed a kind, (GEG) would entail that there is no single relation that all singular terms bear to things in the world which explains why they mean what they do and why human beings use them.

What constitutes a kind here? If we make kinds too general, (GEG) will be too easily true and therefore not distinctive. For instance if we take all terms to form a kind, then nobody will deny (GEG) since nobody thinks that all terms can be explained by their bearing the very same relation to the world. But if we make kinds too narrow, (GEG) will become implausible, because it seems plausible that there are some reasonably unified collections of terms whose meaning can be explained in terms of the same relation with the world. For instance, if we accept Williams's 'RDRD' explanation of the term 'red', there's every reason to think it will work for other colour terms too. If (GEG) blocks this, it is a bad reading of globalism, since Williams himself would not accept it, and nor would Price.

A plausible reading of kinds here is in terms of semantic categories, for instance making the kinds predicates, singular terms, connectives, and so on. On this reading, globalism is the view that there are no relations that can explain all terms of these semantic categories: there's no relation (like reference) that can explain all singular terms, no relation (like satisfaction or description) that can explain all predicates, and so on. This makes sense of globalism. We see globalists denying that we should reach for representation as the key concept in our theory of language - a concept that in its specific forms of reference and satisfaction, or reference and description, would be able to explain language (especially assertions) in general, by explaining the core elements of language - singular terms and predicates. It makes sense that the globalist's point here is that there are just no relations capable of this explanatory work. 
When read in this way (GEG) does indeed conflict with some mainstream theories of meaning. For instance, at least one kind of causal theory of predicate reference seems to violate (GEG), since it takes all predicates to be explained in terms of their causal link with the members of their extension. Moreover, (GEG) is not obviously false; it seems at least (epistemically) possible that there are no general, explanatory relations of the kind (GEG) denies. Indeed, this is part of what local forms of expressivism require, a fact I'll discuss more below.

Strictly speaking, (GEG) does not rule out the view that there are no general relations to the world which explain terms' meanings, but that all the relations which do explain meanings are relations to subject matter. ${ }^{15}$ It is not obvious that all globalists would want to rule this out a priori, but such a view would undermine the local applications of expressivism that globalists want to generalise, since those local applications explicitly deny that the language in question is to be explained in terms of relations to subject matter. So it is more accurate to express globalism as involving the commitment that not all language will be explained in terms of such relations:

(GEG*) There is no term $t$ such that the best explanation of $t$ 's meaning and use requires ascriptions to $t$ of a general relation between language and the world, and there are some terms such that the best explanation of their meaning and use doesn't require mentioning their subject matter

This better captures globalism, by recognising the fact that Price's primary concerns are with the generality of representation and the possibility of explanations of terms which don't put them in relations with their subject matter. And were Price to say that all terms are to be explained by relations to their subject matter, he could retreat to (GEG).

However, even (GEG*) is not good enough: it is not distinct from local versions of expressivism. Consider a metaethical expressivist: he thinks that the meaning of 'wrong' is not explained by its causal link with wrong things. If he thinks that such a causal relation does explain some other terms, say 'tree', and he thinks that 'tree' and 'wrong' are both of the same kind - as they are if we accept the semantic categorisation I discussed - then he already agrees with (GEG*). For he thinks there's no one relation that explains all terms of this kind, since 'wrong' is to be explained differently than 'tree'. And in the ethical case he thinks there's no need to cite a relation between 'wrong' and its subject matter. So this view looks perfectly compatible with (GEG*). Indeed, since (GEG*) no longer says something about all terms, instead saying something about general relations, there is no neat localised version of it, as there was in the case of (GER) and (GSM).

\footnotetext{
15 This kind of view is discussed and rejected by Horwich (1998, 22-3).
} 
Now, in principle a globalist may wish to give a different account of kinds, one that yields a version of (GEG*) localists cannot accept. I cannot rule out all such accounts here. I have argued that the semantic category view is the best way to understand actual globalists' work, so we should stick with it for now. Moreover, other ways face problems. If the globalist takes kinds to encompass terms from different semantic categories, she risks making her thesis too easily true and hence not distinctive - since everyone accepts that, for instance, the logical constants need a different explanation to demonstrative terms. If she takes kinds to be narrow enough that not all terms about the same subject matter will fall within them - so that we might find that ethical terms don't constitute a kind - she risks undermining local applications of expressivism and her own treatment of certain terms, namely those that represent the environment. So at the very least, there is a difficult challenge to meet here. But since the semantic category view is the best reading of actual globalists' work, we can use it from now on, recognising that an alternative view could be developed as a new version of globalism. ${ }^{16}$

\section{The local-global debate}

So far we've seen the following interpretations of global expressivism:

(GEV) No term represents its environment.

(GER) There is no term $t$ such that the best explanation of $t$ 's meaning and use requires treating $t$ as representational.

(GSM) There is no term $t$ such that the best explanation of $t$ 's meaning and use cites $t$ 's subject matter.

(GEG) There is no term $t$ such that the best explanation of $t$ 's meaning and use requires ascriptions to $t$ of a general relation between language and the world.

(GEG*) There is no term $t$ such that the best explanation of $t$ 's meaning and use requires ascriptions to $t$ of a general relation between language and the world, and there are some terms such that the best explanation of their meaning and use doesn't require mentioning their subject matter.

We rejected (GEV) and (GSM) on the grounds that they aren't good interpretations of actual globalist positions, and that they are implausible in any case. (GER) was underdeveloped; (GSM), (GEG), and (GEG*) are developments of it. (GEG) was nearly right, but seemed compatible with the wholesale rejection of actual

\footnotetext{
16 Thanks to two anonymous reviewers for raising issues about kinds.
} 
applications of expressivism and therefore did not capture the spirit of globalism. And (GEG*), which avoided all the problems with the other interpretations, is still too weak because it is compatible with local expressivism, which is meant to conflict with globalism.

This final result is borne out in the literature, which shows that localists like Blackburn and Gibbard are simply talking past globalists like Price. Both Blackburn and Gibbard clearly hold that relations to subject matter are sometimes necessary to explain meaning, yet as we've seen this is compatible with (GEG*)'s global denial of general explanatory relations. However, as we'll see, both Blackburn and Gibbard take expressivism to be about relations to subject matter. They therefore would both take (GSM) to be the proper characterisation of global expressivism and would both reject it. But the same is true of Price: all three of these authors will accept (GEG*) and reject (GSM). Let's now look more closely at Blackburn and Gibbard's work on this topic.

As mentioned in $\S 4$, Blackburn goes so far as to define an expressivist theory of a class of terms as one that

... eschews any use of the referring expressions of the discourse; any appeal to anything that a Quinean would identify as the values of the bound variables if the discourse is regimented; or any semantic or ontological attempt to 'interpret' the discourse in a domain, to find referents for its terms, or truth makers for its sentences. (Blackburn, 2013, 66)

The examples Blackburn gives of theories which violate this condition are cases where a causal relation between a term and its subject matter is necessary to explain that term: 'energies' and 'currents' can only be explained in terms of the fact that 'we have learned to become sensitive to, measure, predict and control, and describe and refer to, energies and currents.' (Blackburn, 2013, 79). So it is clear that Blackburn defines an expressivist theory as eschewing relations between the relevant terms and their subject matter. Therefore, when he denies 'global expressivism', he does not deny what (GEG*) asserts, but instead denies (GSM). He therefore does not disagree with globalism, at least not in its most plausible form. ${ }^{17}$

The same goes for Gibbard, though the route to see this is slightly trickier. Gibbard admits that he uses 'expressivism' differently to globalists like Price. As we saw in $\S 2$, Gibbard takes expressivist theories to be those which 'explain the meaning of the word via explaining the states of mind that constitute believing things couched with the term' (Gibbard, 2015, 212). This looks very much like a

\footnotetext{
${ }^{17}$ Recently Blackburn has begun to say that the view he wants to defend is not so different from Price's, on similar grounds to these. See Blackburn (2017).
} 
global psychologistic theory of meaning: the meanings of words are constituted by their role in expressing mental states. In this sense, however, Gibbard's endorsement of 'global expressivism' has little to do with expressivism as we've been discussing it. So it seems to follow quickly that Gibbard is not disagreeing with the globalists at all, but rather talking past them about a different topic entirely.

Gibbard's project is actually more complex. His aim is not merely to explain words by explaining the states of mind they express; he also requires that we explain these states of mind without citing their content. On his view, we cannot explain ' $\mathrm{x}$ is wrong' just by saying that it expresses the belief that $x$ is wrong $(2015,212)$. But this is still compatible with non-expressivist explanations of those beliefs: we might say that ' $\mathrm{x}$ is wrong' expresses the belief that $\mathrm{x}$ is wrong, and explain the latter belief as a causal or environmental representation of wrongness. Such an account would meet Gibbard's criteria but not be expressivist in the more usual sense. So even with this restriction, Gibbard's idiosyncratic definition of 'expressivism' should be put to one side.

However, Gibbard recognises that his definition is idiosyncratic, and claims that his own view is in fact at odds with globalism as globalists like Price understand it.

Perhaps [Price] uses the term 'expressivism' to exclude giving any notion of representation a genuine explanatory role, a genuine role in explaining meaning. I'm not building this exclusion into the meaning of 'expressivism', and trivially if Price does then the position I am suggesting doesn't qualify as 'global expressivism' in his sense. (Gibbard, 2015, 213)

This makes it seem that Gibbard really will disagree with global expressivism as the globalist understands it. And indeed later on Gibbard endorses 'representationalism' at least in some cases, and claims that his view will involve 'explaining also in terms of representation' (Gibbard, 2015, 215).

So it might seem that Gibbard does deny global expressivism as we've discussed it: he thinks some terms need a representationalist explanation. But on closer inspection there is no disagreement. Gibbard claims that representational terms are ones which causally track the environment. He takes representational thoughts to involve 'a relation to the states of affairs we are thinking about', a relation which is causal $(2015,215)$. Therefore, he thinks that the representational terms are those whose explanation requires (causal) relations with subject matter. And asserting that there are terms whose explanation requires this is, as we've seen, completely compatible with global expressivism as characterised by (GEG*). For invoking relations to subject matter is not the same thing as invoking 
general word-world relations, which are what (GEG*) rules out. So what Gibbard takes to be a denial of global expressivism is just the denial of (GSM), and is completely compatible with (GEG*). Blackburn and Gibbard on the one hand, and Price on the other, are talking past each other: the former deny (GSM), and the latter asserts (GEG*).

Close examination of the literature, therefore, reveals that the actual debate between local and global expressivists is empty, grounded in differing uses of terms like 'expressivism', 'pragmatism', and 'non-'/'representationalism', and indeed 'representation'.

We might be suspicious of this claim. Is there really nothing in, say, Price's globalism which substantially differs from Blackburn and Gibbard's views? One suggestion is that Price is advocating a change in our philosophical project. ${ }^{18}$ Price takes seriously the quasi-realist project in ethics, the project of explaining why ethical attitudes get expressed using declarative claims, which can be embedded in complex constructions, can be called true and false, and so on. He is clear that a key part of his global expressivism is globalising this quasi-realist project: trying to explain why we have any assertions at all. Instead of trying to explain why ethical language is assertoric, he wants to explain why any language at all is assertoric. He describes his view as one that takes the expressivist's 'explanatory stance' towards all kinds of terms rather than just 'special cases' (Price, 2015, 138). ${ }^{19}$ The idea here is to embark on a project of explaining the existence of assertoric language as such, rather than focusing on specific areas like ethical or modal language.

Price argues that local versions of expressivism tacitly assume that some parts of our language are satisfactorily explained using representation. For him this is what local expressivism inherently involves: representationalism about some kinds of language. Price, however, believes that representational notions can never do any explanatory work and that local expressivists themselves show how we can do without them in their non-representational explanations of their chosen kinds of language (e.g. ethics) $(2015,141-3)$. So Price advocates the project of explaining all terms without representational features, and he argues that local expressivism is unstable to the extent that it assumes that some language is explicable in representational terms yet also shows how we can do without representation in their chosen cases.

This proposal to globalise the quasi-realist's explanatory stance does at first look like a genuine departure from the local ambitions of metaethical expressivism. It is certainly a change in explanatory ambition. But it doesn't follow

\footnotetext{
${ }^{18}$ Thanks to an anonymous reviewer for this.

${ }^{19}$ I will mostly refer to Price (2015), since it is a recent and representative paper which itself uses ideas and passages from Price (2013) and other work in Price (2011) including Macarthur \& Price (2007).
} 
that this shift in focus is incompatible with local expressivism. For Price relies on the idea that the global project he recommends does not need representational notions. He says the resulting theory will entirely be 'told in nonrepresentational terms' (Price, 2015, 143), but in the context of this paper this doesn't get us anywhere. For the project of this paper has been to understand what it is to be able give a theory in non-representational terms, as Price puts it - what it is to invoke representation in an explanation. And we've seen that every way of cashing this out makes global expressivism either implausible (by banning explanations which involve environmental representation and the like) or not distinctive.

In other words, if Price explains some terms using relations with their subject matter, then for Blackburn and Gibbard this will not count as a global expressivism. And since Price seems to think this will be so - because there are terms which are 'e-representational' - then for Blackburn and Gibbard the debate is settled. They can carry on being local expressivists by rejecting claims like (GSM), and Price's global expressivism, expressed by this change in project plus the claim $\left(\mathrm{GEG}^{*}\right)$, does not conflict with this at all.

\section{Conclusion}

To sum up, we've found several clear and coherent readings of global expressivism. However, none of these satisfies the four conditions set out in $\S 1$ - none is plausible, a good reading of the literature, distinct from mainstream views, and distinct from local expressivism. (GEG*) seems the most faithful to the most developed form of global expressivism (Price's), and it is clearly an alternative to at least some mainstream theories of meaning, but it is still no real departure from local expressivism. The literature on the local/global debate bears out this result: the debate between the localists and the globalists is merely verbal, about what theories count as expressivist. It turns out that the globalists and localists are like the People's Front of Judea and the Judean People's Front after all - despite the public disputes, there's no real disagreement in doctrine.

This isn't all bad news for globalism. By developing the view we've managed to do away with terms like 'robust' which hindered understanding, attracted criticism, and made the expressivism debate seem inaccessible. And the best developed form of the view, Price's claim (GEG*), isn't obviously false - indeed it is no less plausible than local applications of expressivism. Nor does this render globalism uninteresting. For while (GEG*) may be compatible with what localists typically say, it may be that paying attention to the issue of generality and the explanatory role of representation and the like brings out consequences which the localists themselves fail to recognise, or which local applications of expressivism actually contradict. For example, perhaps many philosophers of language think 
that meaning will typically have to be explained in terms of relations to extensions. Price's reasons for accepting (GEG*) may make us reject this assumption, and this may yield some interesting consequences.

The important thing, then, is not the debate between localists and globalists, but instead the question of whether (GEG*) is true, and if it is, what follows from it. By thoroughly examining the different options, we now have a clear view of the positions defended by globalists and localists alike, and we can now more easily assess these views and their consequences. ${ }^{20}$

\section{References}

Ayer, A. (1936). Language, Truth and Logic (London: Penguin).

Blackburn, S. (1984). Spreading the Word (Oxford: Clarendon Press).

(2010). 'The Steps from Doing to Saying'. Proceedings of the Aristotelian Society, 110, 1-13. Reprinted in his Practical Tortoise Raising: And Other Philosophical Essays (Oxford University Press, 2010), pp. 169-180.

(2013). 'Pragmatism: All or Some?' In Price, H. (ed.), Expressivism, Pragmatism and Representationalism, pp. 59-73 (Cambridge: Cambridge University Press).

(2015). 'Blessed are the peacemakers'. Philosophical Studies, 172 (4), 843-853.

(2017). 'Pragmatism: All or Some or All and Some'. In Misak, C. \& Price, H. (eds.), The Practical Turn: Pragmatism in Britain in the Long Twentieth Century (Oxford: Oxford University Press).

Chrisman, M. (2011). 'Expressivism, Inferentialism, and the Theory of Meaning'. In Brady, M. (ed.), New Waves in Metaethics, pp. 103-125 (Basingstoke: Palgrave-Macmillan).

(2016). The Meaning of 'Ought': Beyond Descriptivism and Expressivism in Metaethics (Oxford: Oxford University Press).

\footnotetext{
${ }^{20}$ For helpful discussion and comments thanks to Simon Blackburn, Tim Crane, Jamie Dreier, Richard Holton, Huw Price, Michael Williams, an audience at the Moral Sciences Club in Cambridge, and several anonymous reviewers. This work was supported by a PhD studentship from the Arts and Humanities Research Council.
} 
deVries, W. A. (2011). 'Review of Huw Price, Naturalism Without Mirrors'. Notre Dame Philosophical Reviews. Accessed at http://ndpr.nd.edu/news/25939-naturalism-without-mirrors/.

Dreier, J. (2004). 'Meta-Ethics and the Problem of Creeping Minimalism'. Philosophical Perspectives, 18 (1), 23-44.

(2018). 'The real and the quasi-real: problems of distinction'. Canadian Journal of Philosophy, 48 (3-4), 532-547.

Gibbard, A. (1990). Wise Choices, Apt Feelings: A Theory of Normative Judgement (Oxford: Oxford University Press).

(2003). Thinking How to Live (London: Harvard University Press).

(2015). 'Global Expressivism and the Truth in Representation'. In Gross, S., Tebben, N., \& Williams, M. (eds.), Meaning Without Representation: Essays on Truth, Expression, Normativity, and Naturalism, pp. 210-243 (Oxford: Oxford University Press).

Gross, S., Tebben, N., \& Williams, M. (eds.) (2015). Meaning Without Representation: Essays on Truth, Expression, Normativity, and Naturalism (Oxford: Oxford University Press).

Horwich, P. (1998). Meaning (Oxford: Oxford University Press).

Jackson, F. (1997). 'Naturalism and the Fate of the M-Worlds'. Aristotelian Society Supplementary Volume, 71, 269-282. Reprinted in Price (2011), pp.132147.

Kraut, R. (1990). 'Varieties of Pragmatism'. Mind, 99, 157-183.

Lenman, J. (2003). 'Disciplined Syntacticism and Moral Expressivism'. Philosophy and Phenomenological Research, 66, 32-57.

Macarthur, D. \& Price, H. (2007). 'Pragmatism, Quasi-realism, and the Global Challenge'. In Misak, C. (ed.), The New Pragmatists, pp. 91-121 (Oxford: Oxford University Press). Reprinted in Price's Naturalism Without Mirrors (Oxford University Press, 2011) pp.228-252.

MacFarlane, J. (2014). 'Review of Huw Price, Expressivism, Pragmatism, and Representationalism'. Notre Dame Philosophical Reviews. Accessed at http://ndpr.nd.edu/news/46002-expressivism-pragmatismand-representationalism/. 
Nye, H. (2015). 'Review of Price, H. Expressivism, Pragmatism, and Representationalism'. Australasian Journal of Philosophy, 94 (1), 196-199.

Price, H. (2004). 'Immodesty Without Mirrors: Making Sense of Wittgenstein's Linguistic Pluralism'. In Kölbel, M. \& Weiss, B. (eds.), Wittgenstein's Lasting Significance, pp. 179-205 (London: Routledge \& Kegan Paul). Reprinted in his Naturalism Without Mirrors (Oxford University Press, 2011), pp.200-227.

— (2011). Naturalism Without Mirrors (Oxford: Oxford University Press).

Price, H. (ed.) (2013). Expressivism, Pragmatism and Representationalism (Cambridge: Cambridge University Press).

Price, H. (2015). 'From Quasi-Realism to Global Expressivism-And Back Again?' In Johnson, R. N. \& Smith, M. (eds.), Passions and Projections: Themes from the Philosophy of Simon Blackburn, pp. 134-152 (Oxford University Press).

Price, H. \& O'Leary-Hawthorne, J. (1996). 'How to Stand Up for NonCognitivists'. Australasian Journal of Philosophy, 74 (2), 275-292. Reprinted in H. Price Naturalism Without Mirrors (Oxford University Press, 2011), pp.112-131.

Ridge, M. (2014). Impassioned Belief (Oxford: Oxford University Press).

Schroeder, M. (2008). Being For: Evaluating the Semantic Program of Expressivism (Oxford: Oxford University Press).

Simpson, M. (2018). 'Solving the Problem of Creeping Minimalism'. Canadian Journal of Philosophy, 48 (3-4), 510-531.

Sinclair, N. (2006). 'The Moral Belief Problem'. Ratio, 19 (2), 249-260.

Toppinen, T. (2015). 'Expressivism and the Normativity of Attitudes'. Pacific Philosophical Quarterly, 96, 233-255.

Williams, M. (2013). 'How Pragmatists can be Local Expressivists'. In Price, H. (ed.), Expressivism, Pragmatism and Representationalism, pp. 113-128 (Cambridge: Cambridge University Press).

Zalabardo, J. L. (Forthcoming). ‘Inferentialism and knowledge: Brandom's arguments against reliabilism'. Synthese. 